\title{
Effects of acetic acid on the total viable counts of microbes and overall acceptability of dressed broiler meat
}

\author{
S A Taher, R Khaton ${ }^{1}$, M A H Fakir, M A Hasnat and M M Rahman \\ Department of Microbiology and Hygiene, ${ }^{1}$ Department of Pathology, Bangladesh Agricultural University, \\ Mymensingh-2202, Bangladesh
}

\begin{abstract}
This study was conducted to evaluate efficacy of acetic acid solution to eliminate pathogens, prevent food deterioration and extend the shelf-life of dressed broiler meat without adversely affecting its quality. A total of 40 broilers were categorized into two groups. Each group was further categorized into two sub-groups: one for intact skin and another for without skin. Each bird of either group viz. comprised of two portions breast and thigh muscle. Acid spray and acid immersion were used. Bacteriological analysis by total viable count (TVC) and sanitary quality determination of dressed broiler by taste panel scores were performed. Acetic acid treatment reduced the initial level of TVC by about 0.5 to 0.724 log colony forming unit (CFU)/gm of meat. Maximum reduction in TVC (0.724) was achieved when acetic acid immersion treatment was given to meat and it was evident that the meat quality of dressed broiler after treatment with acetic acid remains better up to 5 days of storage.
\end{abstract}

Key words: Broiler meat, decontamination, acetic acid, total viable counts.

\section{Introduction}

The recognition of modern concepts about the possibilities for eliminating pathogenic microorganisms from meat has received considerable attention in recent year (Cutter, 1999; Acikgoz et al., 2011). Bacterial contamination of raw processed poultry products continues to be of great concern to consumers and regulatory and health official (Akyurek \& Yel, 2011; Al-Kassi \& Mohssen, 2009; Anower et al., 2004). Despite the hygiene measures applied during processes ranging from slaughtering to packaging, pathogenic bacteria can gain access to carcasses and proliferate on there. Commercial poultry industry is growing rapidly in Bangladesh. Estimate shows that poultry population is increasing at the rate of $6.5 \%$ per year in the country (Haque, 2001). Shelf-life of refrigerated fresh muscle foods is determined mainly by microbiological and physical qualities during storage and handling (Chen and Shelef, 1992). Since the market price of broiler suddenly falls due to unexpected incidents and unforeseen reasons, it is therefore obvious that there occurs problem to sell broiler, as a result, large number of birds necessitate storing for future use. Prolonged rearing of broilers is always unprofitable. In order to obviate the aforesaid problem, if the broilers could be preserved by storing for a certain period of time and sold later, the crisis and anxiety could be overcome, and the poultry farmers could get rid of this loss. Several intervention strategies have been tested and/or adopted for use in eliminating both pathogenic and spoilage bacteria from carcass surfaces. For example, solutions of acetic acid are commonly used by the slaughter industry as antimicrobial spray wash interventions to reduce the microbial load on freshly slaughtered carcasses (Berry and Cutter, 2000). Researchers have shown significant reduction of microbes on fresh meat carcass surfaces after the use of an acetic acid spray (Bacon et al., 1999; Cutter, 1999). The acetic acid is generally recognized as safe substance with no upper limit of daily intake for humans (FAO, 1965). Substantial increases in the occurrence of food poisoning outbreaks and commercial requirements to extend the safe, high quality shelf-life of food have focused attention on decontamination system (Islam et al., 2008; Canibe et al., 2001). The present study is therefore undertaken to determine the effects of acetic acid applied in the raw poultry meat surface and its influence on microbial growth and on meat quality.

\section{Materials and Methods}

A total of 40 broilers were collected from local market. The birds were categorized into two groups, A for control and B for acetic acid treatment. Each group was further categorized into two sub-groups: one for broiler with intact skin and another for broiler without skin. Each bird of either group comprised of two portions namely, breast and thigh. After collection of samples bacteriological analysis and sanitary quality determination were performed for the total viable counts (TVC) by using plate count agar medium to find out the microbiological quality of the meat. Group B was subjected to treatment with $0.5 \%$ acetic acid solution. Two methods of treatment were employed: spray and immersion, performed separately. Group A was kept as control. Samples from Group B after five minutes of treatment was subjected to bacteriological analysis and sanitary quality determination using the same method and 
subsequently kept at $5^{0} \mathrm{C}$ refrigeration by wrapping with commercially available polyethylene bags. Then at $3^{\text {rd }}$ day and $6^{\text {th }}$ day of storage again bacteriological analysis and organoleptic quality determination were performed.

Five taste panel experts determined the organoleptic quality of broiler meats kept at different storage periods by assessing and giving scores of the sensory attributes. There were five qualities characteristics viz. colour, flavour, juiciness, tenderness and firmness or consistency and overall acceptance are considered for the taste panel judgment. For each of the characteristic, the highest score was given 10 marks and the total score was marked 50. Out of 10 marks, 10 is considered as excellent, 8 as good, 6 as fair, 4 as poor, 2 as half spoiled and 0 for spoiled. The taste panel scores of different attributes of the meats of dressed broilers of Group A and B was determined at 1 day, 3 day, 5 day and 7 day. The procedures of examinations were as per the recommendations of ISO (1995), Rahman (1999) and Uddin et al., (2006).

\section{Results and Discussion}

The total microbial load of dressed broiler meat both for de-skinned and intact skinned sample before and after treatment with acetic acid is presented in Table 1. In case of intact skin sample the meat tissue obtained from thigh and breast found to have initial microbial load as log 7.436 and $\log 7.501$ respectively. While in case of without skin broiler meat tissue these values were $\log 7.368$ and $\log 7.416$ respectively. Mohizea et al. (1994) observed the initial total viable count $\left(\log _{10} \mathrm{cfu} / \mathrm{cm}^{2}\right)$ which ranged from log 3.8 to 5.5 with a mean of $\log 4.67$. In the present research work however it was found relatively higher in fresh broiler meat tissue. The table further shows the microbial load in meat of dressed broiler meat given treatment with acetic acid which were determined on $0^{\text {th }}$ day ( 5 min after treatment), $3^{\text {rd }}$ day and $6^{\text {th }}$ day of storage. These counts indicated lower load than that of the control group, indicating the decontamination effect of the organic acid.

Table 1. Total viable counts in the control and acetic acid treated groups of dressed broiler meat at different periods of storage.

\begin{tabular}{|c|c|c|c|c|c|c|}
\hline \multirow[t]{2}{*}{ Dressed broiler } & \multirow[t]{2}{*}{ Treatments } & \multicolumn{5}{|c|}{ Mean TVC * $\pm S D$} \\
\hline & & $\begin{array}{l}\text { Region of } \\
\text { treatments }\end{array}$ & $\begin{array}{l}\text { Control } \\
\text { groups }\end{array}$ & $\begin{array}{l}5 \text { min after } \\
\text { treatments }\end{array}$ & $3^{\text {rd }}$ Day & $6^{\text {th }}$ day \\
\hline \multirow[t]{4}{*}{ With intact skin } & Acetic acid & Thigh & $7.436 \pm 0.091$ & $7.085 \pm 0.07783$ & $7.024 \pm 0.0765$ & $7.125 \pm 0.0694$ \\
\hline & spray & Breast & $7.501 \pm 0.033$ & $7.132 \pm 0.1227$ & $7.076 \pm 0.0998$ & $7.193 \pm 0.0847$ \\
\hline & Acetic acid & Thigh & $7.436 \pm 0.091$ & $6.901 \pm 0.0547$ & $6.712 \pm 0.0538$ & $6.896 \pm 0.0564$ \\
\hline & immersion & Breast & $7.501 \pm 0.033$ & $7.056 \pm .0139$ & $6.861 \pm 0.129$ & $7.007 \pm 0.0996$ \\
\hline \multirow[t]{4}{*}{ Without skin } & Acetic acid & Thigh & $7.368 \pm 0.4328$ & $6.997 \pm 0.0595$ & $6.896 \pm 0.06521$ & $6.993 \pm 0.07512$ \\
\hline & spray & Breast & $7.416 \pm 0.01259$ & $7.048 \pm 0.0850$ & $6.943 \pm 0.0754$ & $7.02 \pm 0.06487$ \\
\hline & Acetic acid & Thigh & $7.368 \pm 0.4328$ & $6.851 \pm 0.1152$ & $6.733 \pm 0.0986$ & $6.78 \pm 0.08775$ \\
\hline & immersion & Breast & $7.416 \pm 0.01259$ & $6.958 \pm 0.06414$ & $6.798 \pm 0.06214$ & $6.869 \pm 0.06345$ \\
\hline
\end{tabular}

* All counts are expressed in logarithms, TVC= total viable counts; SD= standard deviation

These counts indicated lower microbial load in after acetic acid treatment group than that of control group, thus indicating the decontamination effect of acetic acid.

It is evident that in the treated group the TVC were in the highest range on the last day of storage emphasizing the fact that the number of organisms decreased initially due to the antimicrobial effect but on prolonged storage the count gradually increased on the 6th day. This could probably be due to the adaptation of the microbes with the new environment. The result of the study yielded interesting phenomenon to note that the total microbial counts although were found to have increased with the subsequent days of storage, however, the mean TVC on the $6^{\text {th }}$ day of storage were still found to be lower than that of the control, thus indicating the effect of decontamination effect by organic acid. It is an accepted principle that when the microbial load is determined, it needs to make judgment whether the food is safe or not. Hence microbial criteria are established to help make a valid judgment concerning the safety and keeping quality of a food. The total microbial counts of food products not only reflect handling history, state of decomposition or degree of freshness, they may in some instances reflect the sanitary quality of the foods (Dickens et al., 1992).

The determination of total viable bacteria effectively evaluates the hygienic quality of foods (Anower et al., 2004). In this study, the total counts were considered to indicate the nature of sanitary control measures to be exercised in the production, transport and storage of poultry meat. The same may be valid for foods when it is desired to set a standard to be used as a guide to storage life 
(Uddin et al., 2006). However, it is obvious from this research work that the total viable bacterial count as found in dressed birds is not the only criterion that could ensure that the material will be safe consistently; but other quality control tests must be incorporated to make a final judgment for assessing its acceptability and wholesomeness. On the basis of this principle many investigators conducted studies on the incidence of microorganisms associated with dressed poultry (Dickens et al., 1992). The results show that the initial TVC levels were reduced by about $0.50 \log \mathrm{CFU} / \mathrm{g}$ of meat tissue by acetic acid spray treatment while the initial TVC levels declined by 0.61 to $0.72 \mathrm{log}$ CFU/g of meat tissue after acetic acid immersion treatment was employed. The study revealed an important fact that irrespective of the types of treatments employed, TVC were lowest on the 3rd day of storage. This may be due to the combined effect of acid treatment and cold effect of storage. Woolthuis and Smulders (1985) observed in calf carcasses that the total viable count was reduced by 1 log with similar reductions in Enterobacteriace using 1.25\% acid. Bosilevac et al. (2006) found that the lactic acid spray treatment reduced the TVC by $1.6 \mathrm{log}$
CFU/g of meat sample. The present work obtained the reduction of less than 1 log cycle. This may be due to the application or techniques employed for the treatment or may be similar to the observation of Francois (2004) who reported that the decontamination effect of a solution was very much correlated with the $\mathrm{pH}$ of that solution and the chicken meat and skin $\mathrm{pH}$ variation. Comparing initial microbial load present in meat tissues eventually it can be concluded that acid immersion treatment results more in reduction of total viable counts in meat tissues compared to acid spray treatment regardless of intact skin or de-skinned dressed broilers. Francois (2004) observed that decontaminating chicken skin by immersion in an organic acid solution at $7{ }^{\circ} \mathrm{C}$ led to 3.7 decimal reductions in TVC. Similar results were demonstrated by Haque (2007). Anderson and

Taste panel scores of different attributes of the meats of dressed broilers before and after treatment with acetic acid solution and kept for different storage periods is presented in table 2 ..

Table 2. Taste panel scores of different attributes of the meats of dressed broilers before and after treatment with acetic acid solution and kept for different storage periods.

\begin{tabular}{|c|c|c|c|c|c|c|c|c|c|c|c|c|c|c|c|c|c|c|c|c|}
\hline \multirow{2}{*}{ 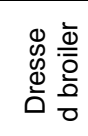 } & \multirow[b]{2}{*}{ RT } & \multirow[b]{2}{*}{ SP } & \multicolumn{3}{|c|}{ Colour } & \multicolumn{3}{|c|}{ Flavour } & \multicolumn{3}{|c|}{ Juiciness } & \multicolumn{3}{|c|}{ TFC } & \multicolumn{3}{|c|}{ OA } & \multicolumn{3}{|c|}{ Total } \\
\hline & & & $\mathrm{C}$ & $\mathrm{T} 1$ & $\mathrm{~T} 2$ & $\mathrm{C}$ & T1 & $\mathrm{T} 2$ & C & T1 & $\mathrm{T} 2$ & C & T1 & $\mathrm{T} 2$ & C & $\mathrm{T} 1$ & $\mathrm{~T} 2$ & C & T1 & T2 \\
\hline \multirow{8}{*}{ 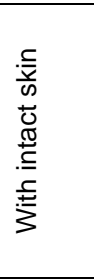 } & \multirow{4}{*}{ 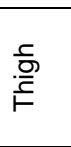 } & 1 & 9 & 9 & 10 & 8 & 9 & 10 & 9 & 9 & 9 & 9 & 9 & 9 & 8 & 9 & 9 & 43 & 45 & 47 \\
\hline & & 3 & 4 & 8 & 9 & 3 & 7 & 9 & 3 & 8 & 8 & 4 & 8 & 8 & 4 & 7 & 8 & 18 & 38 & 41 \\
\hline & & 5 & 2 & 7 & 7 & 1 & 6 & 6 & 1 & 6 & 6 & 1 & 5 & 6 & 1 & 6 & 6 & 6 & 30 & 31 \\
\hline & & 7 & 1 & 3 & 3 & 0 & 2 & 2 & 1 & 3 & 3 & 0 & 2 & 2 & 1 & 2 & 2 & 3 & 12 & 12 \\
\hline & \multirow{4}{*}{ 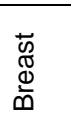 } & 1 & 9 & 9 & 10 & 8 & 9 & 10 & 9 & 9 & 9 & 9 & 9 & 9 & 8 & 9 & 9 & 43 & 45 & 47 \\
\hline & & 3 & 5 & 7 & 7 & 3 & 8 & 8 & 3 & 8 & 8 & 4 & 8 & 8 & 3 & 7 & 8 & 18 & 38 & 39 \\
\hline & & 5 & 2 & 6 & 6 & 1 & 6 & 6 & 1 & 6 & 6 & 1 & 7 & 7 & 1 & 6 & 6 & 6 & 31 & 31 \\
\hline & & 7 & 1 & 3 & 3 & 0 & 2 & 2 & 0 & 3 & 3 & 0 & 2 & 2 & 1 & 2 & 2 & 2 & 12 & 12 \\
\hline \multirow{8}{*}{$\begin{array}{l}\frac{5}{y} \\
\text { D } \\
5 \\
0 \\
0 \\
5\end{array}$} & \multirow{4}{*}{ 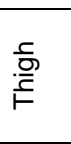 } & 1 & 9 & 9 & 10 & 8 & 9 & 9 & 9 & 9 & 9 & 9 & 9 & 9 & 8 & 9 & 9 & 43 & 45 & 46 \\
\hline & & 3 & 4 & 8 & 9 & 3 & 7 & 7 & 3 & 8 & 8 & 4 & 7 & 7 & 3 & 7 & 8 & 17 & 37 & 39 \\
\hline & & 5 & 1 & 7 & 7 & 1 & 6 & 6 & 1 & 5 & 5 & 1 & 7 & 7 & 1 & 6 & 6 & 5 & 31 & 31 \\
\hline & & 7 & 0 & 2 & 2 & 0 & 2 & 2 & 0 & 2 & 2 & 1 & 2 & 2 & 1 & 2 & 2 & 2 & 10 & 10 \\
\hline & \multirow{4}{*}{ 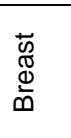 } & 1 & 9 & 9 & 10 & 8 & 9 & 9 & 9 & 9 & 9 & 9 & 9 & 9 & 8 & 9 & 9 & 43 & 45 & 46 \\
\hline & & 3 & 4 & 7 & 8 & 3 & 7 & 7 & 3 & 8 & 8 & 4 & 8 & 8 & 3 & 7 & 8 & 17 & 37 & 39 \\
\hline & & 5 & 1 & 6 & 6 & 1 & 6 & 6 & 1 & 6 & 6 & 1 & 6 & 6 & 1 & 6 & 6 & 5 & 31 & 31 \\
\hline & & 7 & 1 & 3 & 3 & 0 & 3 & 3 & 0 & 3 & 3 & 1 & 2 & 2 & 1 & 2 & 2 & 3 & 13 & 13 \\
\hline
\end{tabular}

* Sensory characteristics with marks:

Excellent $=10 ;$ Good = 8; Fair = 6; Poor $=4$; Half spoiled $=2$; Spoiled $=0$

Legend: RT= Region of treatments; SP=Storage period (days); TFC= Tenderness, firmness and consistency; $\mathrm{OA}=$ Overall acceptance; $\mathrm{C}=$ Control; $\mathrm{T} 1=$ Treatment with acetic acid spray; $\mathrm{T} 2=$ Treatment with acetic acid immersion.

It is evident from the result that the meat quality of dressed broiler after treatment with acetic acid remained better up to 5 days of storage. However, there was no significance difference among the scores achieved by acid spray and immersion treatment of dressed broiler irrespective of dressed broiler with intact skin and without skin. Thus it becomes apparent that the treated meat quality was found better than the untreated one. Moreover, the shelf-life and keeping quality were not only enhanced but there was an obvious reduction of microbial load. Ricke (2003) used 
organic acids to improve the meat and keeping quality of meat. Their findings are similar to the present results.

The present work founds relatively higher microbial load in fresh broiler meat tissue, microbial load in breast muscles was higher than shank muscles, and in dressed broiler with skin was higher than that of dressed broiler without skin. The acetic acid treatment effectively reduces the microbial loads due to its antimicrobial and decontamination effects and emersion treatment was better than its spray. The acetic acid treatment enhances meat quality, the shelf-life and keeping quality of meat in addition to reduction of microbial load.

\section{References}

Acikgon, Z., Bayraktar, H. \& Altan, O. 2011. Effects of formic acid administration in the drinking water on erformance, intestinal microflora and carcass contamination in male broilers under high ambient temperature. Asina-Aust. J. Anim. Sci. 24(1): 96-102.

Akyurek, H. \& Yel, A. 2011. Influence of dietary thymol and carvacol preparation and/or an organic acid blend on growth performance, digestive organs and intestinal microbiota of broiler chickens. Afr.J. Microbiol. Res. 5(8): 979-984.

Al-kassi, A.G. \& Mohssen, M.A. 2009. Comparative study between single organic acid effect and synergistic organic acid effect on broiler performance. Pak. J. Nutr. 8(6): 896899.

Canibe, N., Engberg, R.M. \& Jenson, B.B. 2001. An overview of the effect of organic acids on gut flora and gut heath. Danish Institute of Agric. Sciences, Denmark. 14 pp.

Islam, M.Z., Khandaker, Z.H., Choudhury, S.D. \& Islam, K.M.S. 2008. Effect of citric acid acetic acid on the performance of broilers. J. Bandladesh Agril. Univ. 6(2): 315-320.

Anderson, M.E. \& Marshall, R.T. 1989. Interaction of concentrations and temperature of acetic acid solution in reduction of various species of microorganisms on beef surfaces. J. Food Prot. 52: 312-315.

Bacon, R.T., Sofos, J.N., Belk, K.E., Reagan, J.O. \& Smith, G.C. 1999. Commercial evaluation of multiple-sequential interventions for decontamination of beef carcasses. Beef Program Report. Department of Animal Sciences, Colorado State University, USA.

Berry, E.D. \& Cutter, C.N. 2000. Effects of acid adaptation of Escherichia coli O157:H7 on efficacy of acetic acid spray washes to decontaminate beef carcass tissue. Appl. Environ. Microbiol. 66:1493-1498.

Bosilevac, J.M., Nou, X., Barkocy-Gallagher, G.A., Arthur, T.M. \& Koohmaraie, M. 2006. Treatments using hot water instead of lactic acid reduce levels of aerobic bacteria and Enterobacteriaceae and reduce the prevalence of Escherichia coli 0157: h7 on preevisceration beef carcasses. J. Food Prot. 69(8): 1808
Chen, N. \& Shelef, L.A. 1992. Relationship between water activity, salts of lactic acid, and growth of Listeria monocytogenes in a meat model system. J. Food Prot. 55(8): 574-578

Cutter, C. N. 1999. Combination spray washes of saponin with water or acetic acid to reduce aerobic and pathogenic bacteria on lean beef surfaces. J. Food Prot. 62: 280-283.

Dickens, T.A., Cox, N.A. \& Greer, A. 1992. The effect of air scrubbing on moisture pickup, aerobic plate counts, Enterobacteriaceae and the incidence of salmonellae on artificially inoculated broiler carcasses. Poult. sci. 71(3): 560-564.

Food and Agriculture Organization (FAO) 1965. Specifications for the identity of food additives and their toxicological evaluation: Some antimicrobials, antioxidants, emulsifiers, and stabilizers flour treatment agents, acid and bases. 9th Report of the Joint FAO/WHO Expert Committee on Food Additives. FAO Nutrition Meeting Report Series No. 40.

Francois, D. 2004. Pulsed-vacuum immersion of chicken meat and skin in acid solutions: Effects on mass transfers, colour and microbial quality. Int. J. Food Sci. Technol. 39(3): 277-286.

Haque, M.S. 2007. Efficacy of decontamination of broiler meat organic acids. MS Thesis, Department of Microbiology and Hygiene. Bangladesh Agricultural University, Mymensingh.

Haque, Q.M.E. 2001. Poultry industry in Bangladesh and strategies for its improvement. Proc. $2^{\text {nd }}$ Int. Poultry show seminar held in February 2001, DB Bhaban, Dhaka, Bangladesh.

International Standard Organization (ISO), 1995. Recommendation of the meeting of the subcommittee, International Organization for Standardization, on meat and meat products. ISO/TC-36/Sc-6. PP. 10-18. The Netherlands.

Mohizea, T.S., Mashhadi, A.S., Fawwal, A. \& Al-Shalhat, A. 1994. Microbiological and shelf life assessment of chilled eviscerated whole chicken broilers in Saudi Arabia. British Poult. Sci. 35(4): 519-526.

Rahman, M.M. 2007. Meat Hygiene \& Technology. PP. 273301. Department of Microbiology and Hygiene, BAU, Mymensingh.

Ricke, S. C. 2003. Perspectives on the use of organic acids and short chain fatty acids as antimicrobials. J.Poultry Sci. 82: 632-639.

Uddin, M.K., Rahman, M.M., Ahmed, S.U., Goto, M. \& Rahman, M.H. 2006. Effects of storage conditions on the keeping quality of dressed broilers. J. Bangladesh Soc. Agric. Sci. Technol. 3(1\&2):141-144.

Woolthuis, C.H.J. \& Smulders, F.J.M. 1985. Microbial decontamination of calf carcasses by lactic acid sprays. $J$. Food Prot. 48: 832-837. 